\title{
ESTRATEGIAS PARA LA APLICACIÓN DE PEIRCE A LA LITERATURA
}

\author{
Lucia Santaella Braga
}

(Universidad Católica de São Paolo)

SEÑALES DE ALERTA

El objetivo de la primera parte de mi exposición consiste en aclarar algunos puntos que juzgo fundamentales en la teoría peirceana, alertando contra vicios y confusiones que, por lo regular, surgen cuando se intenta poner en práctica esta teoría con objeto de iluminar específicos procesos sígnicos, en nuestro caso, los procesos sígnicos literarios.

Es conocido el hecho de la gran complejidad de la obra de Peirce, distribuida por los terrenos más variados del conocimiento científico, lo que incluye entre otras áreas a la matemática, la historia, la filosofía, la química, la literatura, la astronomía, etc. Sin embargo, subyace a esta aparente heterogeneidad una especie de columna vertebral a partir de la cual las investigaciones de Peirce confluyeron: la teoría general de los signos concebida como lógica, en un sentido mucho más amplio y generalizado 
del que poseía el término lógica cuando fue concebida por Peirce y del que sigue teniendo hasta hoy.

En primer lugar, debemos destacar que la lógica o semiótica de Peirce es, ante todo, una filosofía, es decir, una teoría que dispone del nivel de generalidad necesario a una teoría filosófica cuyas concepciones, en este caso, fueron trabajadas con el cuidado de la exactitud matemática y cuyas implicaciones fueron desarrolladas tan extensamente como las de cualquier otro pensador monumental de nuestra tradición filosófica occidental. No tenemos ahora espacio para demostrar las afirmaciones arriba expuestas, pues esto nos llevaría a objetivos diferentes de aquellos que, de manera central, nos interesan en esta ocasión. No obstante, a nuestro entender, estas aclaraciones constituyen un punto de partida necesario con relación a cualquier planteamiento respecto a Peirce, habida cuenta de que, el ignorar o comprender indebidamente la base fenomenológica y epistemológica sobre la cual se apoya todo su pensamiento, nos puede llevar a una distorsión que consistiría en asumir la semiótica como simple pirotecnia terminológica, como mera construcción imaginada para dar cuenta de actuaciones instrumentalistas del conocimiento destinadas a un aprovechamiento utilitario e inmediato.

Por el contrario, la semiótica peirceana como filosofía tiene, en su base, la fundamentación necesaria para trabajar los complejos problemas propuestos por la ontología, la epistemología, la filosofía de las mentes, la filosofía de la ciencia y, en fin, por todos los posible despliegues del pensamiento filosófico para los cuales Peirce intentó dar una base común, expuesta en la idea de aquello que concebía como semiosis y que para él podía abordarse como sinónimo de inteligencia, crecimiento y continuidad de la vida. Esta fundamentación se apoya en un método que tiene por intención desarrollar un concepto altamente abstracto de la mente, derivado de un análisis de aquello implícito en la tendencia hacia la verdad que reside en los arcanos de la vida humana.

Éste sería, brevemente, el espectro más amplio de la teoría filosófica peirceana. En esta medida, con relación al conjunto de su obra, el punto de partida de nuestras indagaciones no debería situarse en la descripción de su sistema de clasificación de signos que resultaría inocuo si fuese abordado con una mirada apresurada. Por otro lado, las definiciones y divisiones del signo propuestas por Peirce, al ser abordadas a la luz de su debida fundamentación filosófica, no aparecen como simples clasificaciones strictu sensu, sino como fórmulas para un análisis comprensivo de la acción del signo, patrones que incluyen, como diría Hanna Buczynska (1983:27) «todos los aspectos ontológicos y epistemológicos del universo sígnico, el problema de la referencia, de la realidad y ficción, de la cuestión de la objetividad, el análisis lógico del significado y el problema de la verdad». 
Aunque esta alerta que esbozamos pueda en algunos casos actuar ahuyentando a posibles interesados en la aplicación de los conceptos peirceanos, debemos decir que no hay cómo escapar de la exigencia de explicar la fundamentación filosófica que sostiene estos conceptos, so pena de incurrir en una especie de anemia conceptual que redundaría en la esterilización y vacuidad de tales aplicaciones.

Comprometido con las más diversas prácticas científicas y variados campos de conocimiento, Peirce imaginaba que su vocación más auténtica se desarrollaba en la dirección de concebir un modelo que hiciese posible asumir a la filosofía como ciencia, al mismo tiempo que tal modelo sería capaz de proveer ideas generales, orientadoras del desarrollo de una comprensión genuinamente científica de terrenos extra-filosóficos. En esta medida, la teoría peirceana a pesar de su intrincada complejidad, se nos muestra asentada sobre unos pocos conceptos altamente refinados, elementales, abstractos, generales y dotados de enorme exactitud y sistematicidad. La obsesión peirceana por el refinamiento de cada concepto es indicadora de la consciencia de que cualquier arbitrariedad o ligereza, en la formación del trabajo teórico al nivel fundamental de los conceptos básicos, redunda en incoherencias de la estructura semiótica cuando ésta alcanza el punto de tornarse útil para la aplicación concreta.

Aquello que, a primera vista, parece crear enormes dificultades para la lectura de Peirce, es decir, la extrema generalización y abstracción de sus conceptos fundamentales, es justamente aquello que, una vez asimilado por el lector, pasa a servir de esquema analítico que, debido precisamente a su extrema abstracción, posibilita un espectro extraordinario de aplicaciones posibles. En otras palabras, se trata de un esquema analítico desarrollado sistemáticamente e incorporable por cualquier disciplina particular, especialmente por aquellas que tienen por objeto de estudio fenómenos de naturaleza interpretativa, comunicativa, o semiótica, o sea, aquello que hoy llamamos de ciencias humanas y que Peirce prefiere llamar de ciencias de la vida, incluida la biología.

Así, la semiótica peirceana, lejos de competir con las otras teorías, como algunos imaginan, se propone actuar como una teoría general, interesada prioritariamente en las bases que fundamentan la posibilidad de la inteligencia, así como preocupada en elucidar los métodos que harían ai pensamiento más económico (en el sentido de economía de energía) y más inteligible. Es ésta, entonces, una teoría abstracta que, lejos de excluir los métodos de investigación desarrollados por las ciencias más particulares, necesita de ellos, pues son éstos el material capaz de dar concreción a la abstracción y generalidad de los conceptos semióticos. Así sería la relación del sistema peirceano como sistema abstracto con la teoría literaria, por ejemplo. 


\title{
LA SEMIÓTICA COMO UN MAPA ORIENTADOR
}

En esta medida, sin comprender el carácter sistemático y abstracto de la semiótica peirceana, poco o ningún uso podrá hacer de sus conceptos el investigador interesado en la aplicación práctica. No es casualidad si, a este respecto, J.Ransdell (1983: 12-13) ha afirmado lo siguiente:

\begin{abstract}
Quiero enfatizar en particular la importancia de entender a Peirce sistemáticamente: es casi imposible entender cualquiera de sus concepciones teóricas, al punto necesario, para hacer de ella un uso auténtico, a no ser que también se comprendan las demás concepciones teóricas que están conectadas de manera próxima y sistemática (lecturas y críticas de las concepciones peirceanas que nos demuestran no ser conscientes de sus relaciones sistémicas son la peor cosa que existe, a pesar de que seguramente no sea tarea fácil para aquellos que no están familiarizados en alguna profundidad con el trabajo de Peirce reconocer cuándo un comentarista habla a partir de una comprensión fundamental de esas relaciones). Entender a Peirce sistemáticamente, no significa tampoco memorizar una porción de fórmulas abstractas en un orden determinado. Significa, por el contrario, que una persona sea capaz de aprehender un específico patrón sencillo de relaciones formales que informa a la semiótica peirceana por entero, de tal modo que seamos así siempre capaces de reconocer la presencia de esta postura en todos los modos de hablar y de pensar sobre las cosas que esta persona expresa.
\end{abstract}

Como se podrá ver, aplicar la semiótica peirceana no significa copiar fragmentos de sus escritos, justificándolos por el simple motivo de que determinado fenómeno está siendo objeto de análisis semiótico. Es más, todo fragmento de la teoría peirceana es de un tal nivel de generalidad (sus definiciones de signo, por ejemplo) que resulta posible aplicarlo a cualquier fenómeno sígnico que tengamos en mente. Por lo tanto, citar un fragmento sólo por citarlo, no conduce a nada. Es, además snob, ingenuo e inútil. Aplicar la semiótica de Peirce, por otro lado, no equivale tampoco a rotular los fenómenos sígnicos como procesos definitivamente icónicos, indiciales o simbólicos, como ocurre en los reduccionismos producidos por la mercantilización pedagógica. Estos tres tipos abstractos de signos están presentes en casi todos los fenómenos de lenguaje de manera simultánea.

Contrariamente a estos vicios, que nacen de la opción por lo más fácil y de la ausencia de responsabilidad ética para con una teoría, aplicar los conceptos peirceanos, como en el caso de cualquier teoría muy compleja, exige, ante todo, familiaridad con sus fundamentos, intimidad que nace de la convivencia paciente que permite transformar en extensiones casi naturales de nuestra capacidad indagadora. En la teoría peirceana, según nos informa J. Ransdell (1983: 5): 
Lo que ayudará al lector antes de cualquier cosa, es un estado de alerta y receptividad a un cierto patrón y estructura repetitiva y recurrente que se irá haciendo cada vez más perceptible como informadora de sus concepciones teóricas en sus interrelaciones mutuas y comenzará, en el momento debido, a actuar para el lector como una especie de estructura orientadora básica (es decir, una especie de icono) que será mucho más eficaz para la comprensión de la semiótica peirceana que cualquier formulación verbal abstracta.

Cuando el lector esté equipado por esta estructura básica orientadora habrá captado seguramente el esquema analítico que da forma a la teoría de Peirce. Los conceptos peirceanos son, ante todo, una forma o más bien, un mapa que actúa como medio de orientación para la descripción y análisis de cualquier fenómeno de naturaleza comunicativa e interpretativa. Aplicar la semiótica peirceana significa un estado de familiaridad con este mapa orientador.

Observemos, no obstante, que ese esquema peirceano, asociado a la imagen de un mapa orientador, no ha de ser confundido con un modelo fijo y unitario, aplicable estereotipadamente a la diversidad de los fenómenos. Al contrario, se trata de un conjunto de distinciones analíticas típicas y recurrentes, altamente dependientes de procedimientos heurísticos capaces de permitir la intelección siempre «in fieri» de los fenómenos analizados. Es entonces una teoría desprovista de criterios definitivos y estáticos, que nos provee de instrumentos de estudio sutiles que nos obligan a descubrir y enfrentar las ambigüedades en lugar de ocultarlas.

Sin embargo, si, por un lado, la extrema generalidad de este mapa orientador da espacio para un espectro potencialmente infinito de aplicaciones concretas, por otro, exige, para el análisis, preocupación con estrategias situacionales que sólo pueden ser determinadas por los propósitos que orientan una investigación dada. Para ilustrar esa idea basta citar, por ejemplo, la noción de semiosis, vista como cadena infinita de signos, en la cual la relación entre signo y objeto dinámico se produce como una regresión infinita de signos y la relación del signo con el interpretante entra en una progresión infinita de signos. El objeto original y el interpretante final son así siempre inalcanzables. Ahora, dada una situación concreta de análisis, esto equivale a afirmar que, en cualquier acto de lectura semiótica, estamos siempre comenzando en el medio del camino de la cadena sígnica, que sólo podemos dibujar los lazos de esa cadena (tanto en la dirección del objeto como en la dirección del interpretante) en la medida en que nos interese satisfacer los propósitos con los cuales estamos comprometidos en una situación de búsqueda particular. En términos semióticos, por lo tanto, eso significa que no existen lecturas finales y definitivas de ningún fenómeno. 
Si en la cadena semiótica todo es signo, cabe como estrategia primera, en una situación de análisis dada, determinar aquello que se asume semióticamente como signo, así como sus objetos e interpretantes correspondientes. Esta consideración podría parecer absurda a primera vista. No es el caso. Sorprende porque estamos acostumbrados a considerar como signos los textos (literarios o no), pinturas, películas, obras de teatro, «comics», etc., en definitiva, campos delimitados y recortados. Este vicio que nos condiciona a leer semióticamente tan sólo aquello que se evidencia como signo, nos impide, al mismo tiempo, reconocer las semiosis que pulsan en la «floresta de signos» que llamamos la realidad. En resumen, alertamos aquí sobre el hecho de que el mundo está poblado de signos que actúan en redes intrincadas y complejas. Ante estos tejidos, las relaciones existentes entre signos y realidad que el sentido común nos hace tomar como tácitas e incuestionables aparecen ahora fluidas e interpenetradas, lo que, una vez más, viene a indicar que la actividad de análisis semiótica tiene que ser, ante todo, una actividad heurística.

Colocadas estas señales de alerta, antes de entrar en las cuestiones más ligadas a la literatura, dedicaré una buena parte de mi exposición a la presentación y discusión del contexto más global de la obra de Peirce. Este contexto incluirá un panorama de su biografía, ya que la comprensión de la teorías peirceanas requiere el conocimiento de su vida. Además, algunos esclarecimientos serán ofrecidos con respecto a la bibliografía disponible, hasta hoy bastante parcial, de la vastísima obra de Peirce. Esas informaciones nos parecen indispensables para evitar ingenuidades en el tratamiento de sus teorías. La obra peirceana es inmensa, compleja, intrincada, presentando interdependencia indisoluble entre sus partes. Intentar aplicar Peirce a cualquier área específica, $y$, en nuestro caso, a la literatura, ignorando el contexto general y los fundamentos filosóficos de su pensamiento, trae resultados que son, por lo menos inocuos.

\section{VIDA-OBRA}

Ch. S. Peirce nació en Cambridge (Massachusetts), el 10 de septiembre de 1839. Su abuelo paterno (Benjamín Peirce) fue bibliotecario en la Universidad de Harvard y escribió una historia de esta institución. Su abuelo materno (Elijah H. Mills) era abogado, fundador de una escuela de derecho y senador de los Estados Unidos por Massachusetts. Su tío paterno (Charles H. Peirce) era físico y químico y su tía paterna (Charlotte E. Peirce) mantuvo una escuela al tiempo que enseñaba literatura francesa y alemana en clases particulares. Su tía materna se casó con 
Ch. H. Davis, quien trabajaba para el gobierno federal al servicio de la Inspección Geodésica y de la Costa. El padre (Benjamín) fue profesor de astronomía y matemática en Harvard, considerado en su época como el más sobresaliente matemático norteamericano de entonces. De los tres hermanos de Charles, uno fue profesor de matemáticas en Harvard, otro ingeniero de minas y el tercero, diplomático.

La constelación familiar, que rodea desde pequeño a Charles, nos muestra la variedad de conocimientos, profesiones y experiencias que van desde las ciencias exactas y experimentales a la ingeniería y la política, la diplomacia y la educación. Las relaciones de la familia Peirce no se restringían a su propio ámbito. El padre de Charles, además de respetado científico, era hombre de mente abierta y diversificada. En un ambiente de variados estímulos intelectuales, miembro de una casa visitada siempre por las más importantes figuras del mundo entero, tanto del área de la literatura como de la filosofía y las ciencias, en una atmósfera revolucionaria de conocimientos, $\mathrm{Ch}$. S. Peirce construyó su inteligencia. Desde temprano, entre los hijos, Benjamín reconoció en Charles muestras de genialidad y le dedicó especiales atenciones.

Desde los 6 años, Charles ya poseía, en su casa, un pequeño laboratorio de química y era asesorado en esta actividad, por su tío paterno. A los 11, escribió una Historia de la Química, y a los 16, con la muerte d su tío, heredó de este último una extensa biblioteca de química y medicina. Todo mostraba que Ch. S. Peirce sería en la química una figura tan eminente como su padre en las matemáticas.

En realidad, cuando recibió su diploma en química, Peirce fue el primer estudiante en Harvard en recibir un grado summa cum laude. Su primera publicación profesional, a los 23 años, fue sobre la Teoría Química de la Interpenetración. Pocos años después, antes de completar los 30 años, en junio de 1869 , publicó una tabla de los elementos químicos que alcanzaba de cerca la tabla de Mendeleev, antes de que ésta hubiera sido conocida en Europa Occidental y América.

Entre tanto, el recorrido intelectual de Peirce no conocería el destino de la línea recta.

Preocupado con sobrevivir con sus propios recursos, Peirce se empleó como científico al servicio de la Inspección Geodésica de las Costas. Durante este tiempo, esta actividad lo llevaría de la química a la astronomía, metrología, espectroscopia, geodesia y otras ciencias. Este primer empleo, en sus comienzos provisional, le duraría treinta años. Por algún tiempo, llegó a ocuparse en otro trabajo durante el día en la costa y, por la noche, en el observatorio del Harvard College. Sin embargo, al jubilarse en 1891, Peirce se dedicó inmediatamente a la ingeniería química, volviendo a la profesión que abandonara treinta años antes. Vinculado a esta práctica realizó en esta época una serie de inventos. 
Respecto a su profesión, es decir, con relación a aquello que Peirce realizaría para garantizar su sustento, su biografía se agotaría ahí. No obstante, durante toda su existencia mantuvo intereses de diversidad inimaginable.

Sus investigaciones en la Inspección Geodésica, siempre fueron mucho más allá de lo previsible, hasta el punto de desarrollar importantes trabajos en el área de la óptica, teoría de los colores, proyecciones de mapas, historia de la astronomía y la ciencia en general.

En el campo de la geodesia, metrología y gravedad, Peirce fue, en su época, una figura de renombre internacional, conocido en Londres, Berlín y París. Junto a todo esto, y como herencia inevitable del padre, Peirce fue también un gran matemático, reconocido por su originalidad en este área.

Además de matemático, Peirce fue también físico de importancia. Publicó una serie enorme de investigaciones sobre asuntos relacionados con la física de la gravedad y llegó incluso a ser nominado para ocupar la cátedra de física en la Universidad John Hopkins. Fue también un investigador serio en biología, estimado por sus estudios intensos en taxonomía, bajo la dirección de Agassiz. Estudioso profundo de geología, fue escogido como relator de una disputa entre los dos mayores geólogos de su época. Pero su inquietud intelectual lo llevó igualmente al estudio de las ciencias culturales, conforme se verá más adelante.

Peirce fue, ante todo, un hombre de increíble producción caleidoscópica. ¿Cómo explicar esta miriada ilimitada de inclinaciones e intereses? ¿Sería tal vez por dispersión o por ambición de aparecer un poco en cada espacio y esquina de la ciencia? Ambas alternativas son falsas. La verdad es otra. No obstante, el campo que definitivamente escogiera le fue adverso.

Según Peirce, su más fuerte y profunda tendencia intelectual se inclinaba irresistiblemente para la lógica. $\mathrm{Al}$ ser invitado para hacer cursos temporales en la Universidad de Harvard y en el Instituto Lowell de Boston, entre 1865-70, todas sus conferencias versaban sobre lógica, historia de la lógica o historia de la ciencia. En estas conferencias, se esperaba que el ponente invitado expusiese aquellos asuntos con relación a los cuales pudiese ofrecer una contribución realmente nueva.

Al ser elegido miembro de la Academia Americana de Artes y Ciencias en 1867, Peirce había presentado tan sólo cinco trabajos, todos ellos de lógica. Antes de su elección para la Academia Nacional en 1867, le fue pedido el envío de todos sus trabajos científicos publicados. Peirce se negó a enviar cualquier trabajo, con excepción de cuatro escritos sobre lógica. Por ellos, pretendía ser considerado un hombre de ciencia. 
Como puede verse, esta obstinación no era de cuño personal o individual. Su interés consistía en el reconocimiento de la lógica como una ciencia. Aquí su grandeza y aquí también su irremediable adversidad; no era todavía el momento de la lógica, y mucho menos de la lógica tal como la imaginaba Peirce. No es coincidencia que cuando tuvo un empleo temporal como conferenciante en la pionera Universidad John Hopkins, en Baltimore (1879 a 1884), Peirce se dedicase casi exclusivamente a la lógica.

En 1884, la Universidad John Hopkins clausuró su curso de lógica. Fue aquí cuando Peirce perdió el único y precario encargo que consiguió ocupar en cualquier Universidad del continente americano. No perdió, sin embargo, su determinación en adoptar la lógica como proyecto irrevocable.

En 1892, durante una conferencia en el Instituto Lowell, en Boston, Peirce se expresaba de la siguiente manera: «Soy, ante todo, un estudioso de la lógica y mi devoción la he dirigido especialmente al estudio de la lógica de la ciencia». Esta concepción de lógica como lógica de la ciencia, como arte que iluminaría los métodos de investigación y como campo de investigación en sí mismo, es precisamente la concepción que nos provee la llave para la comprensión de la necesidad peirceana de adentrarse en las diferentes ciencias.

Para Peirce, investigar las diferentes modalidades científicas era una manera de dedicarse a la lógica, es decir, la lógica de la ciencia. Entender esa lógica equivalía a entender los métodos a través de los cuales los resultados son obtenidos en cada disciplina, como contribución sectorial al desarrollo de un todo, inclusive si esos resultados fuesen posteriormente superados. Condición necesaria aunque no suficiente para comprender estos métodos, era practicarlos. Los métodos difieren mucho de una ciencia a otra y, de tiempo en tiempo, dentro de una misma ciencia. Lo que es común a todas las ciencias sólo puede ser divisado por alguien que conozca las diferencias y que comprenda, desde la práctica, los varios métodos utilizados ahora y en el pasado.

El campo peirceano muestra dos facetas por un lado, la práctica de las diversas ciencias y, por otro, la historia de la ciencia. Su carrera científica multiforme, no fue fruto de triviales y fortuitas circunstancias, sino un camino planificado.

La dedicación deliberada a variados terrenos lo apartó de la gloria más fácil, de esto Peirce era consciente. No obstante, desistir de la lógica sería para él una lucha insensata. No desistió. Pagó, en consecuencia, el precio de la soledad (vivió recluido voluntariamente, junto a su segunda mujer, durante los últimos veinte años de su vida), realizando trabajos que, cuando eran publicados, producían incomprensión o, a veces, parcos comentarios irónicos. Ni la humillación de la miseria, ni la fragilidad de 
un cuerpo enfermo y vulnerable, al final de su vida, consiguieron deternerlo. Sólo paró con la muerte.

Fue apenas en 1911, tres años antes de morir, cuando Peirce consiguió el reconocimiento público como lógico; no obstante, no fue sino después de muerto cuando Charles Sanders Peirce comenzó a ser llamado filósofo.

\section{OBRA-VIDA}

Sólo recientemente, como fruto de décadas de incansables investigaciones hechas por grupos de estudiosos norteamericanos, se pudo conocer, que, al morir, Ch. Peirce dejó escrito y publicado durante su vida, repartidos en las más diversas revistas científicas y filosóficas de su época, lo que sumaría algo así como unos 800 artículos y ensayos, lo que representa aproximadamente unas 12.000 páginas impresas. A 500 páginas por volumen, una edición completa de sus escritos publicados alcanzaría un total de 24 volúmenes.

No obstante, nunca podremos saber con exactitud el número de manuscritos que Peirce dejó de publicar y que, poco después de su muerte, Juliette, su segunda mujer, entregó a la biblioteca de Harvard. Aquello que fue preservado y que ya se encuentra hoy enteramente catalogado, llega a un total de 80.000 páginas. A razón de una página impresa por dos manuscritas, tendríamos entonces 80 volúmenes adicionales de trabajos no publicados que, sumados a los otros 24 , llegarían a un total de 104 volúmenes.

Esto nos da una idea de la gigantesca producción de este pensador. La magnitud de su obra está emergiendo recientemente con el concurso de muchos estudiosos; este trabajo disipará los malentendidos, incomprensiones, lecturas fragmentarias e incluso inmaduras que, desde hace un siglo, oscurecen, si no totalmente, por lo menos en parte, la nitidez del horizonte de la obra peirceana.

El primer intento con objeto de proporcionar una idea bibliográfica general de los textos que Peirce publicara en vida fue realizado por Morris Cohen, en un artículo escrito en 1916. Pertenece también a este autor una primera pequeña antología (Azar, Amor y Lógica, por Ch. S. Peirce), publicada en 1923 (Nueva York). Durante algún tiempo, iniciativas de organizar y publicar fragmentos de los escritos de Peirce fueron frustradas, hasta que, al final de los años 20, Hartshorne y Weiss, dos jóvenes filósofos de Harvard, editaron los Collected Papers, 6 volúmenes que aparece- 
rían entre 1931 y 1935 . Los volúmenes 7 y 8 fueron editados en 1958 por A. Burks. Desde entonces, otras antologías aparecieron, usando siempre como referencia los Collected Papers.

Hasta poco tiempo atrás éstas fueron las únicas selecciones de escritos peirceanos que circularon y trajeron a la luz una pequeña parcela de la inmensa obra de este pensador (nótese que los Collected Papers representan apenas unas 4.000 páginas de las 92.000 escritas por Peirce).

Si bien los Collected Papers recogen los trabajos más importantes que Peirce publicara en vida, constituyen tan sólo una pequeña selección de los escritos no publicados. Por otro lado, la selección fue realizada tomando en cuenta bloques temáticos integrados con criterios más o menos arbitrarios.

El trabajo de los Collected Papers, tuvo merecido valor 50 años atrás, pero ahora se sabe que hay rupturas de continuidad y elipsis brutales, lo que puede acarrear equívocos y malentendidos, que ya llevaron a algunos a pensar que la obra de Peirce es fragmentaria, incompleta y oscura.

Debemos alertar sobre el hecho de que a pesar del valor evidente del trabajo de compilación realizado en los Collected Papers, éstos no ofrecen ni siquiera una pálida idea de la coherencia y del crecimiento continuo y autocorrectivo de la obra de Peirce.

Infelizmente, la publicación impresa del conjunto íntegro de sus escritos, presenta todavía enormes obstáculos. Sin embargo, existen otros factores que deben ser considerados, para entender la demora de la divulgación honesta de esta producción.

En primer lugar, tenemos que considerar la fuerza de un prejuicio, que casi siempre actúa por vías subliminales y que se traduce en la creencia de que un país como los Estados Unidos, sin tradición filosófica secular, no puede generar un gran pensador. A esto se suma el hecho de que una formidable popularidad acogió, de inmediato, la obra del pragmaticista William James, considerado por muchos como un seguidor de Peirce. Pero, en verdad William James produjo una filosofía psicologizante, en antagonismo evidente con el pensamiento peirceano. Además, la primera divulgación interpretativa de la obra de Peirce que gozó de popularidad, fue la de $\mathrm{Ch}$. Morris, que redujo el pensamiento peirceano a una especie de mezcla de positivismo y behaviorismo.

Por otra parte, la lectura de los textos de Peirce, sin duda, es ardua e intrincada. Trataremos de dar aquí una explicación aproximada de las razones de estas dificultades: toda teoría revolucionaria es, por naturaleza, oscura y perturbadora. Si no fuese así, nada traería de nuevo y no sería, por lo tanto, revolucionaria. En esta medida, toda nueva teoría exige decifración. Surge, de hecho, como una especie de criptograma. Por otro la- 
do, un pensamiento verdaderamente original nunca es esperado. Si lo fuese no sería original.

Entre tanto, la fuerza histórica de un pensamiento auténtico - aunque nacido a deshora - termina por encontrar su lugar en el reloj del mundo.

De hecho, hace cerca de quince años, se inició un proceso para el redescubrimiento de la obra peirceana el cual crece gradualmente. Al principio, los primeros trabajos de exégesis de su pensamiento surgieron en el campo de la filosofía. Esto es curioso, ya que, mientras estaba vivo, en ningún momento llegó a ser reconocido como filósofo. Es suficiente un breve contacto con algunos de entre sus miles de escritos para que el lector inmediatamente se dé cuenta de que está frente al diálogo de un solo hombre con 25 siglos de tradición filosófica occidental.

Por tal razón, Peirce fue objeto, como filósofo de las rotulaciones más discrepantes: desde idealista absoluto hasta empirista radical, desde neoplatónico hasta una suerte de nuevo-Hume, desde neohegeliano hasta neo-positivista... Sólo actualmente la originalidad de la tarea, que él se propuso en términos filosóficos, está siendo evaluada, es decir, el acercamiento a la filosofía a partir de las ciencias, a través de las ciencias y como una ciencia. Es cierto que esto Peirce, más que nadie, podría reivindicarlo y, de hecho, realizarlo, por la radical singularidad de sus prácticas científicas y filosóficas. Además de haber sido un hombre de laboratorio, familiarizado con las experimentaciones y los raciocinios prácticos, que le hicieron desarrollar con rapidez la capacidad de liberarse del lastre de creencias, en el momento en que la experiencia las comprobase endebles, era también matemático, acostumbrado a articular su raciocinio dentro de los patrones de investigación capaces de sorprender improcedencias en la construcción de cualquier pensamiento, fuese o no matemático.

Peirce también llevó ese tipo de espíritu de investigación al campo de la filosofía. «Estudié filosofía en la medida en que ella es también una ciencia exacta; no de acuerdo con las nociones de prueba infantiles de los metafísicos, sino de acuerdo con la lógica de la ciencia».

Desde los tiempos de Peirce, la expresión «lógica de la ciencia» entró en desuso, y el término «lógica» vino a significar «lógica deductiva» o «lógica matemática en forma algebraica». Aunque él mismo hubiera contribuido en el desarrollo de la lógica algebraica y, dentro de la lógica deductiva, hubiese creado un «sistema de grafos existenciales», sistema, según él, superior a la lógica algebraica como instrumento para el análisis conceptual, todas estas incursiones fueron la vía para subsidiar su proyecto central: producir una metodología lógica tan vasta, profunda y económica que pudiese servir de fundamento para cualquier investigación científica, inclusive filosófica y también las literarias. 
Hasta poco tiempo atrás, la recepción de la obra de Peirce era asumida de dos maneras. Dado el hecho de que Peirce trabajó en tan variadas áreas, un cierto número de investigadores, especialmente dentro de los Estados Unidos, dio a conocer aspectos de esta obra (principalmente las consideraciones de orden filosófico) de manera inorgánica y sin mención a la teoría general de los signos y al papel que la semiótica ocupa en la arquitectura global de la teoría peirceana. Por otro lado, fuera de los Estados Unidos, se divulgaba estrictamente su semiótica (a partir, en el mejor de los casos, de los C. Papers), desconociendo las bases filosóficas y su importancia para la comprensión de la propia formulación semiótica.

Hoy, ese cuadro dividido y desviante ya muestra cambios alentadores, en la medida en que las fuentes para el estudio de Peirce resultan cada vez más accesibles, lo que debería modificar el carácter de las investigaciones sobre su semiótica y su obra en general (cf. sobre esto The New Tools of Peirce Scholarship, Fisch et al. 1979).

\section{LO QUE HAY DE LITERATURA EN PEIRCE}

Después de un viaje de tren, viniendo de Viena, durante el cual se casaron; Roshana y Karolo Kalerger llegaron a la casa en Praga al atardecer, y ella quedó encantada con la casa y mobiliario. Mal probaron la comida que les estaba esperando, cuando ella se levantó para retirarse diciendo:

«Debo vestir la ropa persa que usé en casa del ladrón?»

«Sí, claro; es lo correcto.»

«Entonces, usted puede venir dentro de media hora.»

Él pasó ese tiempo como mejor pudo. Removió las zapatillas. Se aseó. Pero diez minutos antes del tiempo convenido, entró en el «boudoir». Ella lo esperaba de pie. Él se aproximó y la atrajo hacia él en un abrazo apretado. La acostó en el diván, pronunciando palabras que le venían de lo hondo de su corazón. En un gesto desastrado por la pasión, la linda ropa de seda se rompió de arriba abajo. Ella sonrió.

«iPor Dios!», murmuró él, «ipensé que sólo en el Olimpo se supiese lo que es la fiesta del vivir!».

$\mathrm{Y}$ así permanecieron en las delicias del placer, hasta el apaciguamiento del deleite y hasta que el compañerismo viniese a amenizar los decretos del poder más alto del deseo.

Con el fragmento anterior, uno entre los dos finales posibles, de una novela escrita por Peirce, Christian J. W. Kloesel, director del Peirce 
Edition Project ${ }^{1}$, dio inicio a un artículo sobre los manuscritos peirceanos. Con el título de Ideas, Stray or Stolen, about Peirce's Writings: $n .^{\circ} 2$ (Ideas, Extraviadas y Robadas, sobre los Manuscritos de Peirce: $n^{\circ} 2$ ), tal artículo fue presentado en el I Seminario Internacional de Estudios Avanzados de Semiótica, realizado en Aguas de Sao Pedro, en la Pontificia Universidad Católica de Sao Paulo y en la Universidad de Sao Paulo, de 15 a 22 de agosto de 1990, bajo la organización del programa de estudios de postgrado en Comunicación y Semiótica de la PUCSP. El número 2, en el título del artículo, indica la existencia de un artículo anterior sobre el mismo asunto, que fue presentado por el autor durante el IV Congreso Internacional de Semiótica, realizado en Barcelona-Perpignan, en marzo de 1989.

En la continuidad de su artículo de número 2, Kloesel nos informa sobre el número del manuscrito, 1.561, donde aparece la novela escrita por Peirce, y sobre el contexto que lo llevó a escribirla. Aunque sea ampliamente conocida la espantosa superabundancia y versatilidad de la producción peirceana, no deja de ser sorprendente que, al morir, entre las 90.000 páginas de manuscritos no publicados, también haya dejado una novela. Al final, ¿qué podría llevar a un matemático, químico, físico, astrónomo, lógico, filósofo e historiador a meterse en la escritura de ficción a los 50.años de edad?

El título de la novela es Thessalian Topography: A traveller's Tale (Topografía tesalonicense: El cuento de un viajero), tiene 80 páginas y fue escrita en un único día. Kloesel nos dice que:

\begin{abstract}
Peirce quedó tan impresionado con Tesalónica, sus alrededores y con la ciudad de Larisa, los cuales, en septiembre de 1870, exploró como una posible estación de observación para un eclipse total de sol, visto por él tres meses y medio más tarde, el 22 de septiembre, en Sicilia...; tan fuertemente impresionaron su imaginación que, veinte años más tarde, un «Día del Trabajo», en 1890, escribió su novela, «con bordados ficcionales», como dijo, «para dar una idea (del espíritu) del lugar y de las personas... y para expresar el sentimiento que suscitaron fuertemente (en mí)... el sentimiento que naturalmente se conecta con... este país poético en el escenario, en su historia, y en la singular mezcla de audacia y gentileza de carácter de su población actual».
\end{abstract}

Para aquellos que tienen mayor familiaridad con la vida y obra de Peirce ${ }^{2}$, el hecho de que él haya sido llevado a escribir una ficción no

1 El Peirce Edition Project es un proyecto editorial en funcionamiento desde 1976, en Indianápolis, Universidad de Indiana, USA. Ese proyecto prevé publicar, en 30 volúmenes, la edición cronológica de los textos más importantes dejados por $\mathrm{Ch}$. S. Peirce. Son 4 los volúmenes publicados hasta ahora. El quinto volumen está siendo impreso, y se espera que la colección completa sólo esté finalizada alrededor de la segunda década del próximo siglo.

2 No podría dejar de anotar que las fuentes, que he utilizado para tener acceso a los datos biográficos de Peirce, son todas ellas procedentes de los escritos de Max H. Fisch (1977, 1978, 1982,1983 y 1986), sin ninguna duda el más profundo y sensible conocedor de la vida y obra de Ch. S. Peirce. 
llega a ser tan sorprendente como puede parecer a primera vista. Aunque Peirce haya sido, antes que nada, un científico, habiendo llevado su espíritu de científico tanto hacia la lógica como a la filosofía, en ningún momento de su vida, fue excluido de sus preocupaciones e intereses aquello que hoy llamamos las humanidades o ciencias humanas. Sus pesquisas cuidadosas y originales en el área de la psicología lo hicieron el primer psicólogo experimental de los Estados Unidos. El valor de sus investigaciones como historiador y, más especialmente, como historiador de las ciencias fue recientemente puesto de relieve en el admirable trabajo de Carolyn Eisele (1985). No pueden tampoco ser ignoradas sus exploraciones en el campo de la filología y lingüística. Peirce conocía más de una decena de idiomas, entre los cuales, evidentemente, el latín y el griego eran dominados con desenvoltura. Llegó a desarrollar parte de una gramática del árabe y, entre sus millares de escritos, hay un ensayo sobre la pronunciación del griego antiguo. Para tener una idea de lo temprano que su pasión por las estructuras, inclusive lingüísticas, despertó, baste decir que, a los 18 años de edad, Peirce ya se dedicaba a la invención de un lenguaje artificial.

En medio de todo eso, sin embargo, no son en modo alguno despreciables las incursiones de Peirce por la literatura. Su padre, Benjamín Peirce, era también un amante de la literatura, teatro y otras artes, tanto así que fue miembro de una asociación literaria en Harvard junto a las más reconocidas figuras del mundo literario americano de la época. No causa extrañeza, sin embargo, que la primera publicación profesional de un Peirce todavía muy joven haya sido en química, y la segunda sobre La Pronunciación Shakesperiana. Además, sus pesquisas sobre dicción poética, con sus estudios sobre el tiempo, ritmo y frecuencia de sonidos, siempre fueron muy elaboradas. No raras veces también, acompañó a su segunda mujer, Juliette, a Nueva York, donde ella tuvo, durante algún tiempo, clases de representación dramática con Steele Mackaye. En esas ocasiones, Peirce llegó a hacer lecturas públicas de la tragedia Rey Lear, precedidas de charlas sobre la dicción poética y acción dramática de la obra. Pero su interés por el universo del drama no paró ahí. A los 65 años, comenzó a escribir una obra de teatro. Además de eso, practicaba el arte quirográfico y, lector asiduo de E. A. Poe, tradujo quirográficamente algunos de sus cuentos.

Por fin, no se puede dejar de señalar que la literatura interesaba a Peirce más de lo que acostumbraba generalmente a interesar a los hombres de ciencia. Aunque su escritura no raras veces llega a alcanzar niveles de poeticidad, sobre todo cuando busca ejemplos para ilustrar y dar forma sensible a la aridez conceptual de sus definiciones generalizadoras, Peirce estaba lejos de ser un literato, tanto en términos teóricos como prácticos. No hay duda de que no era en dirección de la literatura en la que corría la vertiente de su deseo. Siendo así, ¿qué puede justificar el tí- 
tulo y tema de este seminario «Peirce y la Literatura»? Eso es lo que trataré de discutir en seguida.

\section{LA LITERATURA EN EL ESCENARIO DE LAS CIENCIAS}

Durante toda su vida, Peirce luchó en pro del reconocimiento de la lógica como ciencia. Sin embargo, muy temprano en su vida intelectual, Peirce se dio cuenta de la parcialidad de las lógicas que solamente consideran los signos simbólicos. Para él, no hay ningún método, ningún raciocinio, ningún pensamiento, ningún lenguaje que se pueda procesar apenas en signos simbólicos, o sea, que no haga uso de otros tipos de signos además de los símbolos. Esa lógica de sentido lato, que tiene como tarea, antes que nada, abarcar las leyes generales de todas las especies posibles de signos, Peirce la bautizó de semiótica, siguiendo el rastro dejado por Locke.

Infelizmente, sin embargo, por más que Peirce haya luchado, durante su existencia entera, para abrir camino a la aceptación de la lógica en el sentido vasto en que la concibió, él no llegó a lograr para esa lógica ni siquiera la más elemental comprensión. El testimonio que, casi al final de su vida, Peirce da sobre eso a Lady Welby ${ }^{3}$ es triste e irónicamente ilustrativo:

Mi querida Lady Welby, tú mereces esta provocación, por haber dicho que «yo siempre estuve bondadosamente (!!!) interesado por el trabajo al que mi (de Lady Welby) vida se consagrón, cuando yo mismo estuve absorbido por ese mismo y exacto asunto desde 1863, sin que hubiese encontrado, antes de nuestro contacto, una única mente a la cual mis ideas no hubiesen sonado como la más pura tontería. (Hardwick 1977: XXVI)

3 En 1906, Peirce reseñó el libro What is meaning, de la autora inglesa Victoria Lady Welby. Desde entonces, se inició, entre ambos, un intercambio de correspondencia que duró hasta 1911 , cerca de la muerte de Lady Welby, ocurrida en 1912, dos años antes, por lo tanto, de la muerte del propio Peirce. El contenido de la correspondencia comprueba que una gran amistad intelectual y personal fue naciendo y sedimentándose entre ambos. Buena parte de la doctrina general de los signos fue escrita en las extensas cartas de Peirce para Lady Welby. La correspondencia muestra también que el sello de esa amistad funcionó como un bálsamo que trajo mucho calor humano a Peirce en los miserablemente difíciles últimos años de su vida. Nunca llegaron a conocerse personalmente, aunque hubiesen planeado un encuentro, durante un viaje que Peirce y Juliette debían hacer a Europa, pero que nunca se efectuo, dado el estado de casi indigencia al que Peirce quedó reducido. Hay que observar que Lady Welby y Josiah Royce fueron los únicos interlocutores que Peirce encontró para sus formulaciones semióticas. 
Si Peirce no mereció reconocimiento en vida, ni como lógico, ni como filósofo, eso ahora solamente puede servirnos como indicio del poder anticipador de su pensamiento. De hecho, hasta dos o tres décadas atrás, la empresa de traer a la luz y descifrar las ideas de Peirce, en cierta forma, quedó bajo el monopolio de los filósofos. No fue, sin embargo, a través de la filosofía como Peirce llegó a ser conocido en todo el mundo, sino justa e imponderablemente por el nombre que escogió para bautizar a su lógica en sentido lato, la semiótica. Cabe recordar que el término semiótica no había aparecido una única vez en las 12.000 páginas de textos que Peirce publicó en vida. Sus estudios sobre semiótica se concentraron en los manuscritos no publicados. ¿Cómo podrían Peirce y sus contemporáneos imaginar que sería exactamente la semiótica, la más incomprendida e ignorada de sus invenciones, la responsable del gran impulso de reconocimiento, por el cual su obra iría a pasar, muchos años después de su muerte?

Cuando la explosión de estudios semióticos tanto de raigambre centroeuropea, cuanto de raigambre soviética comenzó a cobrar importancia en el escenario intelectual de las humanidades, a fines de los años 60 e inicio de los 70, el nombre de Peirce y su hoy famosa clasificación de signos en iconos, índices y símbolos fue apareciendo cada vez con más frecuencia. El carácter pionero de su esfuerzo por la creación de una doctrina general de los signos fue siendo reconocido y su papel de fundador de la semiótica celebrado.

Todas las corrientes y vertientes de las teorías semióticas no peirceanas, aunque ellas se definan dentro de una base linguiística, o narratológica, o culturalista, o psicológica, comparadas al nivel de generalidad de la doctrina peirceana de los signos, se caracterizan más exactamente como ciencias especiales o semióticas especiales, dado el hecho de que son teorías que trabajan con campos y procesos específicos de signos. La considerable diferencia de niveles de abstracción teórica entre la doctrina peirceana y de las demás corrientes semióticas (diferencia que, a mi modo de ver, es enorme), infelizmente pasó desapercibida de los semioticistas.

Durante muchos años, su semiótica fue tomada como comparable —en términos de finalidades a las que se destina - a las otras teorías semióticas. Una vez que a la doctrina de Peirce le falta especificidad y consecuentemente poder descriptivo, querer forzarla para entrar en un molde que no es el suyo, se asemeja a la vana tentación de coger peras del olmo. Por esa razón la mayor parte de las aplicaciones de sus clasificaciones de signos, llega, en la mayoría de los casos, a resultados decepcionantes hasta el punto de que su clasificación se parece mucho más a una especie de repetición estéril, que a herramientas analíticas iluminadoras. 
Aunque no se pueda negar la existencia de muchos estudios que hacen uso heurístico y creativo de las categorías clasificatorias de Peirce, hay que apuntar a una tendencia disfuncional y equivocada de las finalidades que su sistema se propone alcanzar. La razón principal de esas distorsiones radica, tanto cuanto puedo ver, en la ignorancia involuntaria, aunque sistemática, por parte de los semióticos, del lugar ocupado y papel desempeñado por las clasificaciones de signos, en el contexto más amplio de la propia semiótica peirceana, y de ésta, en el contexto de su arquitectura filosófica, así como del lugar y papel de esa arquitectura en el contexto de la clasificación de las ciencias. Lo que ha contribuido a la no superación de ese estado de cosas es el divorcio que se instauró entre la naturaleza de la investigación, dentro de la obra de Peirce, que los filósofos han llevado a efecto, y las preocupaciones, en general más prácticas, que llevan a los semióticos a utilizar los conceptos peirceanos.

En vista de eso, el objetivo prioritario de esta parte de mi exposición es el de contextualizar la semiótica peirceana, dentro del cuerpo más amplio de su arquitectura filosófica, insertando esa arquitectura en el diagrama más vasto de la clasificación de las ciencias que fue elaborado por Peirce a lo largo de 47 años. En ese diagrama, que él pretendió que fuese lo más amplio, flexible y dinámico posible encontraremos las varias y diferentes posiciones que deben ser ocupadas por la teoría, la crítica y el hacer literarios, así como las modalidades heuréticas, de divulgación y las aplicadas de la teoría literaria, incluyendo los niveles nomológico (teorético), clasificatorio y descriptivo o explicatorio de esa misma teoría.

La máxima pragmática a que llegó Peirce, después de 50 años de trabajo intelectual, lo llevó a creer que cualquier creencia dada puede ser entendida en términos de la red de relaciones que ella mantiene con otras ciencias. Una vez que las ciencias son interdependientes, una clasificación diagramática de ellas, tendría por función exhibir los principios de esa interdependencia, y apuntar los efectos concebibles de cada ciencia.

Tengo fuertes sospechas de que Peirce estaba en lo cierto al apostar por las ventajas que el diagrama clasificatorio de las ciencias puede traer tanto para la comprensión de la ciencia con la cual cada investigador trabaja y de las relaciones que cada ciencia mantiene con las demás, cuanto puede contribuir al conocimiento de cuáles ciencias proporcionan principios a otras, y cuáles proporcionan datos y sugestiones a otras, según veremos con más detalles más adelante.

Es innegable que, de un lado, las falacias del positivismo y, de otro, la división del trabajo intelectual, en el siglo $\mathrm{xx}$, que departamentalizó el conocimiento y las ciencias en compartimentos estancos e incomunicables, están tan arraigados en nuestro espíritu que nos llevan a no creer en cualquier posibilidad de interdependencia de las ciencias. Reina, entre 
nosotros, además de eso, en el ambiente intelectual contemporáneo, un acuerdo consensual en cuanto a las separaciones rígidas entre las llamadas ciencias «hard» y las llamadas ciencias «soft», con cierto desprecio mal oculto por el lado «soft», que llega al punto del rechazo total a la aceptación de que éstas tengan derecho al mero nombre de «ciencia». Como si esto no bastase, no podemos dejar de convenir que las llamadas ciencias humanas están, de hecho, sumergidas y tienden a sumergirse cada vez más en una generalizada confusión en cuanto a la demarcación de sus fronteras, aliada a una tendencia a la divergencia entre ellas, paradójicamente en el momento mismo en que las ciencias «hard» tienden a una creciente convergencia.

Ahora bien, el espíritu que preside la clasificación de las ciencias elaborada por Peirce funciona como un verdadero antídoto contra esos problemas. Su clasificación de las ciencias explicita las relaciones de interdependencia de una ciencia para con las otras, indicando los escalonamientos en niveles de abstracción a través de los cuales las ciencias más abstractas funcionan como fundación para las menos abstractas, en la medida en que es de las más abstractas que las más concretas toman sus principios, al mismo tiempo que es con los datos proporcionados por las ciencias menos abstractas que las más generales se abastecen. Dentro de ese cuadro, no hay ninguna razón para que la literatura deje de comparecer en la clasificación peirceana de las ciencias. Pero para mejor comprender por qué tal ausencia no se justifica, es necesario abrir aquí un breve paréntesis.

No hay nada más deliberada y naturalmente liberal que la concepción peirceana de las ciencias. Ninguna camisa-de-fuerza, a no ser las inevitables restricciones de la realidad, les es impuesta de fuera para inhibir la maravillosa libertad, vigilada por el rigor, que es la única y gran fuerza de aquellos que son devorados por el deseo de la verdad. «Distender el arco de la verdad con atención en la mirada y energía en el brazo» es todo lo que basta para hacer de alguien un científico, no importa cuán precarios y limitados sean sus conocimientos, cuando da inicio a su jornada. La sed de aprender, la curiosidad del conocer orientan sus pasos. Es por eso por lo que, para Peirce, nadie además del propio científico, con la ayuda de la crítica honesta de sus pares, puede dictar reglas para el hacer de la ciencia. Ciencia no se confunde con conocimiento acumulado (esto es apenas el residuo o excremento de la ciencia), pero es aquello que los científicos vivos hacen. Es, por consiguiente, un modo peculiar de acción y de conducta. La ética de la ciencia brota, así, de dentro del hacer científico. Actividad cuya honra mayor reside en el ideal siempre in futuro de la verdad y en la rara capacidad de despojamiento de las creencias más queridas, en el momento en que los hechos las prueben inoperantes. 
Si la ciencia es aquello que los científicos vivos hacen, y científico es aquel que se mueve por la sed de la verdad, a los oídos de Peirce la división actual entre ciencias «hard» y «soft» sonaría ridícula. Además de eso, está lejos de su concepción la sobrevalorización instrumentalista de la ciencia, que también reina entre nosotros. Siendo así, carecería de sentido excluir la literatura del cuadro general, dinámico y evolutivo de las ciencias tal como fue diseñado por Peirce.

En razón de lo que aquí quedó expuesto, se ve claramente por qué mi exposición no podría llamarse «Semiótica y Literatura», o «Semiótica de la Literatura», o «Semiótica Literaria». Mi pretensión o ambición aquí es un poco más vasta y menos específica. Por un lado, se trata de alertar sobre la necesidad de rescatar la inserción de la semiótica peirceana en el cuadro más completo de su sistema filosófico. Por otro, se trata de exhibir el diagrama de las ciencias, buscando evidenciar las contribuciones que el sistema filosófico de Peirce, con su nacimiento en la fenomenología, su espina dorsal en la estética, ética y lógica o semiótica, con su corazón en la semiótica y su expansión en la metafísica, pueden prestar a las ciencias especiales, entre ellas la ciencia de la literatura. Esto es lo que trataremos de hacer en lo que sigue.

\section{UN SISTEMA PARA EL PENSAMIENTO CIENTÍFICO}

Hablar de Peirce, por lo menos para aquellos que tuvieron algún contacto con su obra, significa hacer una alusión automática a su conocido sistema de clasificación de signos (icono, índice y símbolo). Sin negar la importancia de ésta y otras clasificaciones por él establecidas, debemos decir que no es siempre éste el mejor camino para iniciarse en el pensamiento peirceano. Más importante para comenzar, nos alerta J. Weinsheimer (1983:228), es prestar atención al «contexto de su pensamiento» que da fundamento y sentido a toda su teoría y por supuesto, a la semiótica.

Peirce comenzó a estudiar lógica hacia los 12 años de edad. Pocos años después, los estudios intensos de las cartas de Schiller lo llevaron hasta Kant, cuya Crítica de la Razón Pura ya sabía de memoria con apenas 18 años. Su primera publicación profesional, en el campo de la lógica, se produjo en 1866, a los 27 años, con el título de Memoranda sobre el Silogismo Aristotélico. Ese mismo año escribiría otro ensayo, Un Método para la Búsqueda de las Categorías. Este texto puede abordarse como una especie de tubo de ensayo para la elaboración de su trabajo fundamental, Sobre una Nueva Lista de Categorías, que aparecería un 
año después, y que debemos considerar como un verdadero sistema nervioso central de todo el conjunto de su obra. Este ensayo, aseguraba Peirce, era producto de la más intensa diligencia intelectual que jamás hubiera realizado. Él pretendía aquí iluminar las categorías más universales, capaces de abarcar todas las experiencias posibles. Utilizando la misma terminología aristotélica (hai Kategoriai) y Kantiana (Die Kategorien), por comparar sus propios propósitos a los de estos pensadores, Peirce, no obstante, imaginaba su empresa como un proyecto mucho más ambicioso y radical que aquellos soñados por Aristóteles y Kant o inclusive Hegel.

Como punto de partida, Peirce se dedicó a interpretar la propia experiencia despojado de presupuestos de cualquier especie. Consideró como entidad experimentable al fenómeno. Sin condiciones preestablecidas imaginó que su noción de fenómeno constituía un concepto tan amplio que en ningún momento podríamos limitarlo a sensaciones, percepciones o inferencias cuales fueren, localizables espacial y temporalmente. La idea de fenómeno trasciende las constataciones de lo que el sentido común acostumbra a llamar «mundo real». Para Peirce el fenómeno es toda y cualquier cosa que aparece ante nuestra mente, bien se trate de un sueño, una alucinación, una imagen, un olor o una idea general y abstracta.

Como procedimiento Peirce realizó el más atento y microscópico examen de la manera en que los fenómenos pueden ser experimentados. Este examen tenía como objeto revelar los diferentes tipos de elementos detectables en los fenómenos para, posteriormente, agrupar esas características en clases más amplias y universales (categorías) presentes en todos los fenómenos y así establecer sus modalidades de combinación.

Para Peirce, «este análisis radical de todas las experiencias es la primera tarea a la cual la filosofía debe someterse. Es una tarea difícil, tal vez la más difícil de las tareas, exigiendo poderes de pensamiento peculiares, la habilidad de atrapar nubes vastas e intangibles, organizarlas a través de sus ejercicios» (CP:1.280). El producto de este desafío llevó a Peirce a asegurar que sólo existen tres únicos elementos formales o categorías universales (omnipresentes) de modo gradual en todos los fenómenos. Debe quedar claro que estas categorías no son formalizaciones rígidas y puras. Existen infinitas modalidades de categorías particulares que habitan en todos los fenómenos. Se trata de categorías «tan elementales y generales, que pueden ser vistas más como tonos, humores o finos esqueletos del pensamiento que como nociones definitivas» $(C P: 1.355)$. Las categorías serían algo así como especies de puntos en dirección a los cuales los fenómenos tienden a converger, ofreciéndonos focos para localizar los nervios del mundo.

Terminado el estudio, a pesar del rigor incorruptible que en él empeñara, Peirce juzgó haber sido víctima de una ilusión. Reducir la variedad de 
los fenómenos a tres únicos elementos le parecía una fantasía absurda. Dieciocho años más tarde, en 1885, Peirce produjo otro ensayo: $1,2,3$ : Categorías fundamentales del Pensamiento y de la Naturaleza (MS:901). Las categorías, descubiertas en 1867 a través del análisis lógico del fenómeno mental, volvían ahora con más rigor, extendidas a toda la naturaleza. Su precaución natural, reforzada por su temperamento científico, lo condujeron, a lo largo de treinta años, a buscar la verificación empírica de las categorías en los campos más variados. Su conjunto de categorías, extraídas del análisis lógico, no deberían, según Peirce, ser aplicadas a todos los seres, sin una verificación empírica previa.

La lógica, la fisiología, el protoplasma, la física, la psicología, la metafísica, etc., áreas que Peirce conocía en profundidad, iban confirmando la universalidad de sus categorías. Éstas eran las vías empíricas de conformación, ya que las denominaciones analítico-deductivas Peirce las desarrolló en su «teoría de los grafos». Las denominaciones, que las categorías recibieron a lo largo de su obra, varían en la medida en que asumen matices diferenciados, dependiendo del campo o fenómeno que les da cuerpo. A pesar de esa variabilidad material el substrato lógico-formal siempre permanece, de ahí que Peirce hubiera escogido la denominación lógica de primeridad, segundidad y terceridad de acuerdo con la noción más abstracta de valencia. La valencia de primero está aliada a la noción de azar, potencialidad, indeterminación, espontaneidad, cualidad, presencia, mónada... La valencia de segundo se vincula a las ideas de fuerza bruta, esfuerzo y resistencia, acción y reacción, aquí y ahora, díada... La valencia de tercero se corresponde con las nociones de generalidad, crecimiento, continuidad, representación, mediación, tríada...

\section{SEMIÓTICA: ÉTICA DEL INTELECTO}

Cabe esclarecer que fue justo en esa tercera categoría lógica (crecimiento continuo) en la que Peirce encontró su definición de signo genuino como proceso relacional de tres términos o mediación que lo condujo a la noción de semiosis infinita o acción dialéctica del signo. Hacia 1900, Peirce ya discriminaba, con mucha claridad, dos especies de acción interactivas en el universo: acción bruta o diádica (causación eficiente) y acción dialéctica, triádica o inteligente (causación final). A partir de ahí, estableció la más minuciosa arquitectura clasificatoria de las ciencias. Para él, las ciencias se dividen en tres grandes troncos: ciencias del descubrimiento, de la divulgación (o digestión) y ciencias aplicadas. Detengámonos, como él hizo, en las del descubrimiento que son: matemáticas, filosofía y ciencias especiales e idioscópicas. Estas últimas las 
dividió en físicas y naturales en todas sus modalidades (predominio de la causación eficiente) y «psíquicas», del griego psiqué, esto es, principio de vida, en todas las modalidades (predominio de la causación final).

1. Ciencias del descubrimiento.

1.1. Matemáticas.

1.2. Filosofía.

1.3. Idioscopia o ciencias especiales.

1.3.1. Ciencias físicas.

1.3.2. Ciencias de la vida o psíquicas.

Para su filosofía científica, Peirce configuró una estructura que tiene, en la doctrina de las categorías (por él denominada, en 1904, de «phaneroscopia») su base de sustentación. Sobre ese principio, asentó, entonces, los tres grandes troncos de las ciencias filosóficas, de la siguiente manera: la estética como base de la ética y ésta como base de la semiótica. En esa medida, la estética (ciencia de lo admirable) domina la primera categoría, así como la ética (ciencia de acción y conducta) domina la segunda categoría y la semiótica domina la tercera categoría. No en vano Peirce llegó a declarar que la semiótica no era otra cosa sino una ética del intelecto.

1.2. Filosofía.

1.2.1. Fenomenología.

1.2.2. Ciencias Normativas.

1.2.2.1. Estética.

1.2.2.2. Ética.

1.2.2.3. Lógica o Semiótica.

Fue sólo después de esas minuciosas clasificaciones cuando Peirce, él mismo, consiguió vislumbrar y estar alerta a la coherencia del crecimiento continuo con que sus ideas habían brotado en el correr de su vida. Tiempo de inflexión y reflexión, que él vino a denominar «tiempo de cosecha». Sólo entonces, Peirce vio claro el lugar y el papel de la semiótica en el conjunto de su obra, como el lugar de ésta en el diagrama más global de las otras ciencias. En estado de indescriptible fertilidad, de 1903 a 1909 , se dedicó a la teoría general de los signos con una persistencia obsesiva que apenas los héroes, santos y locos deben, de cerca, conocer.

Consciente de que su vocación más auténtica era la de un lógico, la ambición de Peirce, al principio, era la de fundar, sobre nuevas y más 
vastas bases, la lógica deductiva, inductiva y abductiva (o lógica de las hipótesis) dentro del marco de una teoría general de los signos y de las representaciones. Hacia 1900, con todo, pasó a discriminar los sentidos para la lógica: un sentido amplio en que la lógica es sinónimo de semiótica y un sentido restringido, dentro del cual la teoría unificada de la deducción, inducción e hipótesis, entonces denominada lógica crítica, pasaría a ser la segunda de las tres ramas de la semiótica. En la primera rama estaría la gramática especulativa, en el sentido teorético (del griego theoretikos), o sea, la teoría de la naturaleza de las relaciones de representación y de los varios tipos de signos o procesos de semiosis (éste es el lugar, por lo tanto, de sus clasifíicaciones de signos). La tercera rama correspondería a la retórica especulativa o metodéutica que investiga la eficacia de la semiosis. La lógica del descubrimiento, la teoría de la investigación y el arte de la comunicación entrarían dentro de la metodéutica.

\subsubsection{Lógica o Semiótica.}

1.2.2.3.1. Gramática Especulativa.

1.2.2.3.2. Lógica Crítica.

1.2.2.3.3. Metodéutica.

Todo ese campo vasto cubre lo que Peirce llamó «Semiótica General». Distinguía esa teoría formal y filosófica, de las ciencias psíquicas o vitales que cubrirían todas las ciencias sociales y psicológicas en sus varias especies. Por ser esas ciencias especiales diferenciadas y particulares modalidades de semiosis. Peirce juzgaba que la Semiótica General, con relación a ellas, podría ser utilizada como un subsidio analítico para la descripción y revelación de sus objetos particulares. La concepción peirceana de una Semiótica General era, por lo tanto, configurar una fundación básica y conceptos sistemáticos capaces de hacer la filosofía científica, al mismo tiempo que creadora de ideas-maestras que pudiesen estimular el desarrollo de una comprensión genuinamente científica en los campos extra-filosóficos, particularmente de aquellos cuyos objetos de estudio son primeramente de naturaleza representativa, interpretativa o comunicativa.

El deseo de Peirce (pues él también tenía deseos) era el de que su sistema filosófico-científico, con la semiótica en el corazón de este sistema, pudiera funcionar como fundación ontológica y epistemológica (una epistemología sígnica, por demás), para todas las ciencias especiales, entre ellas, la literatura (en todos sus niveles, es lo que se puede añadir a su proyecto ahora, conforme veremos).

Tendríamos entonces algo que se puede ver en el cuadro completo de su sistema: 
1. Ciencias del descubrimiento

1.1. Matemáticas

1.2. Filosofía

1.2.1. Fenomenología

1.2.2. Ciencias Normativas

1.2.2.1. Estética

1.2.2.2. Ética

1.2.2.3. Lógica o Semiótica

1.2.2.3.1. Gramática Especulativa

1.2.2.3.2. Lógica Crítica

1.2.2.3.3. Metodéutica

\subsubsection{Metafísica}

1.3. Idioscopia o ciencias especiales

1.3.1. Ciencias Físicas con sus clases

1.3.2. Ciencias Psíquicas

1.3.2.1. Teorética

1.3.2.2. Clasificatoria

1.3.2.3. Descriptiva

2. Ciencias de divulgación

3. Ciencias Aplicadas

El cuadro anterior es sólo una representación esquemática. No cabe aquí profundizar sobre los ensayos y variaciones a que Peirce fue sometiendo sus esquemas a través de los años, como fue competentemente explorado por Beverly Kent, en su importante libro Charles $S$. Peirce. Logic and the Classification of the Sciences (1987). Cabe aquí tan sólo poner el énfasis en el hecho de que Peirce, evidentemente, incluyó la literatura en esas clasificaciones. Una vez que la clasificación es natural, esto es, relativa a las actividades a las que los científicos vivos de su tiempo se dedicaban, la literatura aparecía en el elenco de las ciencias especiales, del ramo de las ciencias psíquicas, en el siguiente punto de la clasificación:

1.3. Ciencias especiales

1.3.1. Ciencias Físicas

1.3.2. Ciencias Psíquicas

1.3.2.1. Teoréticas

Psicología General

Sociología General

Economía General

etc. 


\subsubsection{Clasificatorias \\ Psicología Especial \\ Lingüística \\ Etnología \\ etc. \\ 1.3.2.3. Descriptivas o Explanatorias \\ Historia \\ Biografismo \\ Crítica de la Literatura \\ etc.}

De acuerdo con Peirce, cuanto más las ciencias se localizan en lo alto de las jerarquías, más abstractas son, y más capaces también de proporcionar los principios generales sobre los cuales se fundan las ciencias más concretas en un escalonamiento gradual. Así, la matemática y filosofía, con todas sus subdivisiones, incluyendo la semiótica y sus tres ramas, proporcionan subsidios para las ciencias especiales, del mismo modo que, dentro de las ciencias especiales, las teoréticas fundamentan los niveles clasificatorios y éstos los descriptivos o explicativos. Así, por ejemplo, la psicología general, la sociología general y la economía general proporcionan principios y leyes generales a las ciencias de los tipos o ciencias clasificatorias, tales como la psicología especial, la linguíística, la etnología. Éstas, a su vez, fundamentan las ciencias descriptivas, entre las cuales se destacan: la historia (inclusive la historia de la literatura, ciertamente), la biografía y la crítica literaria y de las artes.

Conviene observar, sin embargo, que según Peirce, cuando llegamos al nivel de las ciencias especiales, el papel de la filosofía científica como fundamento, ahí comienza y ahí se acaba. Ella suministra principios, pero no interfiere en la vida de las ciencias, ya que éstas quedan bajo la responsabilidad exclusiva de aquellos que las practican. Siendo así, la relación entre la filosofía semiótica y las ciencias especiales es una relación dialógica. Por un lado, las ciencias filosóficas proporcionan principios, por otro, reciben información de las ciencias especiales para completar los detalles de sus conceptos generales.

Hay todavía otro aspecto que merece ser mencionado. Si mantenemos la idea peirceana de clasificación natural de las ciencias, observando ahora lo que los hombres produjeron dentro de lo que podría ser llamado «ciencias literarias», en el transcurso del último siglo, o sea, la proliferación y multiplicación diferenciada de manifestaciones teóricas de la literatura, puede llevarnos a postular la hipótesis de que la literatura, hoy, es, por sí sola - en las diferentes formas actuales de desdoblamiento de sus producciones a nivel de teoría, crítica, análisis de textos, divulgación periodística, etc. - capaz de rellenar todos los niveles de ciencias psíquicas 
propuestos por Peirce, en igualdad de condiciones y posibilidades de relaciones dialógicas con las otras ciencias psíquicas. Así tendremos: 1.3.2.1. el nivel teorético, recubriendo todo el campo de las diferentes teorías literarias; 1.3.2.2. el clasificatorio, recubriendo los estudios de los géneros, de las formas literarias, por ejemplo; 1.3.2.3. el nivel descriptivo, englobando la crítica literaria, el análisis de textos, el comentario, etc., en fin, el examen de textos singulares existentes, manifestaciones individuales, tales como una novela, un poema, etc.

Además de eso, tendríamos la posibilidad de pensar las diferentes manifestaciones de la literatura en el nivel 2 , también como ciencia de divulgación, donde estarían situados los trabajos de divulgación de descubrimientos en el ámbito de las teorías literarias, y la difusión, a partir de ellas, de nuevas filosofías literarias, nuevas mentalidades, nuevas formas de sensibilidad. En el nivel 3, ciencias aplicadas, en el caso de la literatura, tendríamos sus aplicaciones, por ejemplo, a la pedagogía, o los usos posibles de la literatura como terapéutica, etc.

Evidentemente, los niveles más abstractos de la jerarquía, esto es, los niveles teóricos y clasificatorios, así como los descriptivos, son, cuando se trata de la literatura, retroalimentados, ante todo, por las producciones del arte literario en sí, aquello que los escritores y poetas crean. Son también las obras literarias - el arte del hacer literario -- las que ofrecen indicios, materiales y detalles sígnicos concretos para el estudio de los conceptos generales del vasto sistema filosófico-semiótico propuesto por Peirce. En la relación entre las ciencias, el mismo movimiento dialógico se repite: al mismo tiempo que extraen sus fundamentos de los conceptos generales proporcionados por las ciencias filosóficas, las ciencias especiales regresan a ellas con aportaciones de detalles y ejemplificación de los conceptos.

Para finalizar, por lo tanto, se puede afirmar que la relación entre Peirce y la Literatura se revela como un inmenso campo de investigaciones posibles, que van más allá de un mero análisis de texto, sin anularlo, evidentemente, una vez que éste se incluye entre las ciencias descriptivas literarias. Un amplio campo de investigación se puede abrir, por ejemplo, para estudiar las relaciones de la fenomenología peirceana con la literatura, en sus niveles (teorético, clasificatorio y descriptivo). Otro campo también amplio y complejo, y que presupone el anterior, es el de las contribuciones de la estética peirceana a los estudios de la literatura, también es sus varios niveles. Otro vastísimo campo, que presupone los dos anteriores, conforme manda la lógica fenomenológica, es el de los estudios de la semiótica peirceana aplicada a los tres niveles de la literatura. Este campo se desdobla todavía en las tres ramas de las semiótica: 1. en la gramática especulativa, donde se tiene la contribución de las clasificaciones de los signos para los estudios literarios; 2 . en la lógica crítica, el estudio de los tipos de raciocinio o métodos (abductivo, inductivo y deduc- 
tivo), tal como se manifiestan en el universo literario (tanto en la creación literaria cuanto en su teoría). Entonces, en la metodéutica, tendríamos los estudios de los efectos significados de las producciones literarias, esto es, su eficacia comunicativa, sus formas de recepción. Por fin, en la metafísica peirceana, encontramos fuentes conceptuales seguras para pensar las grandes cuestiones, los grandes temas de la literatura: el mortal y el perenne, el trinomio verdad-ficción-realidad, azar vs. elección, etc.

En fin, las sugerencias anteriores, presentan una primera cartografía del territorio, sin detallar sus minucias e implicaciones. Lo que se puede afirmar, en conclusión, es que el horizonte que se presenta en las relaciones posibles entre Peirce y la Literatura es amplísimo. Para divisarlo, no obstante, no es aconsejable que el investigador, principiante en la cuestión, vaya con mucha sed al pozo. Es necesario conceder, antes, a la obra de Peirce el tiempo de estudio y paciencia para el aprendizaje que ella exige y merece.

\section{Referencias bibliográficas}

BuCzynska-GarewiwCZ, H. (1983): «Sing and dialogue». American Journal of Semiotics, vol. 2, n. ${ }^{\circ}$ 1-2, 27-43.

EISELE, C. (1985): Historical Perspectives on Peirce's Logic of Science. A History of Science, 2 vols. Berlín: Mouton.

FISCH, M. H. (1977): «Peirce's Place in American Thought». Ars Semiotica 1/2, 21-37.

- (1978): «Peirce's General Theory of Signs». En Sight, Sound, and Sense, Thomas A. Sebeok (ed.). Bloomington: Indiana Press, 31-70.

- (1982): «Peirce's Place in American Life». Historia Mathematica 9, 265-287.

- (1983): «Just How General is Peirce's General Theory of Signs». American Journal of Semiotics, vol. 2, $\mathrm{n} .^{\text {os }} 1-2,55-60$.

- (1986): Peirce, Semeiotic, and Pragmatism. Essays by Max H. Fisch, Kenneth L. Ketner and Christian J. W. Kloesel (eds.). Bloomington: Indiana Press.

FISCH, M. H. et al. (1979): «The New Tools of Peirce's Scholarship». En Peirce Studies 1, 1-17.

HARDwICK, Ch. S. (ed.) (1977): Semiotic and Significs. The Correspondence between Charles S. Peirce and Victoria Lady Welby. Bloomington: Indiana Press.

Kent, B. (1987): Charles S. Peirce. Logic and the Classification of the Sciences. Kingston and Montreal: MacGill-Queen's University Press.

PeIRCE, Ch. S. (1931-1958): Collected Papers. vols. 1-8, C. Hartshorne, P. Weiss, and A. W. Burks (eds.). Cambridge, MA: Harvard University Press. La sigla CP refiérese los Collected Papers, MS a los manuscritos inéditos.

RANSDell, J. (1983): Peircean Semiotics. Copia en xerox de un trabajo no ultimado.

Weinshemer, J. (1983): «The Realism of Ch. S. Peirce, or how Homer and Nature can be the same». En American Journal of Semiotics, 2, 1-2, 225-264. 